Meta

Journal des traducteurs

Translators' Journal

\title{
Breve historia de la secretaría de interpretación de lenguas
}

\section{Ingrid Cáceres Würsig}

Volume 49, numéro 3, septembre 2004

L'histoire de la traduction et la traduction de l'histoire

History of Translation and Translation of History

URI : https://id.erudit.org/iderudit/009381ar

DOI : https://doi.org/10.7202/009381ar

Aller au sommaire du numéro

Éditeur(s)

Les Presses de l'Université de Montréal

ISSN

0026-0452 (imprimé)

1492-1421 (numérique)

Découvrir la revue

Citer cet article

Cáceres Würsig, I. (2004). Breve historia de la secretaría de interpretación de lenguas. Meta, 49(3), 609-628. https://doi.org/10.7202/009381ar

\section{Résumé de l'article}

Cet article retrace l'histoire du Secretaría de Interpretación de Lenguas (Secrétariat à l'interprétation de langues) qui fut créé par Charles Quint en 1527 pour épauler le Consejo de Estado (Conseil d'État). Ce Secrétariat peut être regardé comme une organisation pionnière en Europe en matière de traduction « officielle ». Il est à l'origine de la traduction assermentée dans la péninsule Ibérique. Parallèlement au Secrétariat à l'interprétation, les traductores de Estado (traducteurs d'État) commencent, dès le début du XVIII ${ }^{\mathrm{e}}$ siècle, à travailler pour d'autres organismes officiels, activité qui est également décrite. La fin du XVIII ${ }^{\mathrm{e}}$ siècle voit naître un nouveau cas de figure en Espagne, le jeune de langues, qui peut être considéré comme le premier échelon de la carrière diplomatique. En particulier, nous répondrons aux questions suivantes : quand et pourquoi fut créé un service de traduction et interprétation officiel en Espagne? Quelles étaient ses missions ? Qui travaillait dans ce service et comment y accédait-on ? Quels types de documents et langues étaient traduits ? Comment étaient rémunérés ces travaux?
Ce document est protégé par la loi sur le droit d'auteur. L’utilisation des services d’Érudit (y compris la reproduction) est assujettie à sa politique d'utilisation que vous pouvez consulter en ligne.

https://apropos.erudit.org/fr/usagers/politique-dutilisation/ 


\title{
Breve historia de la secretaría de interpretación de lenguas
}

\author{
INGRID CÁCERES WÜRSIG \\ Universidad Europea de Madrid, Madrid, España \\ ingrid_c@ti.fil.uem.es
}

\begin{abstract}
RÉSUMÉ
Cet article retrace l'histoire du Secretaría de Interpretación de Lenguas (Secrétariat à l'interprétation de langues) qui fut créé par Charles Quint en 1527 pour épauler le Consejo de Estado (Conseil d'État). Ce Secrétariat peut être regardé comme une organisation pionnière en Europe en matière de traduction «officielle». Il est à l'origine de la traduction assermentée dans la péninsule Ibérique. Parallèlement au Secrétariat à l'interprétation, les traductores de Estado (traducteurs d'État) commencent, dès le début du XvIII siècle, à travailler pour d'autres organismes officiels, activité qui est également décrite. La fin du XVIII ${ }^{e}$ siècle voit naître un nouveau cas de figure en Espagne, le jeune de langues, qui peut être considéré comme le premier échelon de la carrière diplomatique. En particulier, nous répondrons aux questions suivantes: quand et pourquoi fut créé un service de traduction et interprétation officiel en Espagne? Quelles étaient ses missions? Qui travaillait dans ce service et comment y accédait-on? Quels types de documents et langues étaient traduits? Comment étaient rémunérés ces travaux?
\end{abstract}

\section{ABSTRACT}

The article traces the history of the Secretaría de Interpretación de Lenguas (Language Interpreting Secretariat), which was created by Charles V in 1527 to support the Consejo de Estado (Council of State) and which can be considered as a pioneering organization in Europe in the field of "official" translation. Here we can find also the origin of the sworn translation in the Iberian Peninsula. At the same time and from the 18th century socalled traductores de Estado (State translators) started to work directly for other state offices, whose activity is also described. At the end of the 18th century a new figure emerges, namely the joven de lenguas (jeunes de langues), which can be considered as the first step in the development of the diplomatic career. More specifically, the following main questions will be answered: When and why was an official translation and interpreting service first created in Spain? What was its incumbent? Who worked for this service and how did applicants enter the office? Which languages and what type of documents were translated? How were these linguistic services remunerated?

\section{MOTS-CLÉS/KEYWORDS}

histoire de la traduction, diplomatie, administration, origine de la traduction assermentée

\section{Introducción}

Es un hecho demostrable que la investigación en el campo de la historia de la traducción se ha centrado hasta el momento sobre todo en la historia de la traducción literaria. Curiosamente la traducción e interpretación practicada fuera de este ámbito, ya sea en las administraciones de las diferentes naciones, en los consulados, embajadas, notarías, chancillerías, ${ }^{1}$ etc. - que posiblemente haya sido muy superior en volumen a la traducción literaria - está mucho menos explorada. No vamos a detenernos aquí 
a analizar las causas de este desequilibrio; simplemente señalar que se trata de un campo con grandes posibilidades de investigación, pues todas las naciones se han servido de traductores e intérpretes como instrumentos de mediación en la comunicación interestatal desde épocas muy tempranas.

El caso de España es singular pues desde 1527 existe un organismo específico dedicado a la traducción de documentos estatales, cuyo origen, evolución y funcionamiento se tratará de sintetizar en este artículo. La historia de este organismo ha podido ser trazada gracias a documentos inéditos que he encontrado repartidos en distintos archivos históricos: el Archivo Histórico Nacional, el Archivo General de Simancas y el Archivo del Ministerio de Asuntos Exteriores. En ellos se encuentran los expedientes personales de los traductores e intérpretes que trabajaron en dicho organismo así como los expedientes de los llamados jóvenes de lenguas nombrados a finales del siglo XVIII. Asimismo existe el propio archivo de la Secretaría de Interpretación de Lenguas, que reúne todos los borradores de los documentos traducidos desde 1773, además de varios libros de registro que aportan información muy valiosa sobre la historia de dicho organismo.

\section{El nacimiento de la Secretaría de Interpretación de Lenguas}

Como consecuencia de las intensas relaciones interestatales que se desarrollan a finales del siglo XV gracias al impulso dado por los Reyes Católicos se hace patente la necesidad de una mediación lingüística entre los incipientes estados modernos. Los mencionados monarcas crean una importante red de embajadas y embajadores dispersa por toda Europa (Escudero, 1976: 69). Posteriormente, Carlos V ampliará esta red y al traer consigo numerosos consejeros extranjeros, sobre todo borgoñones, italianos, flamencos y alemanes, implanta un sistema polisinodial para gobernar sus reinos tanto en razón de espacios geográficos como, por ejemplo, el Consejo de Indias o el Consejo de Aragón, como de materias, por ejemplo, el Consejo de Cruzada ${ }^{2}$ o el Consejo de Inquisición ${ }^{3}$ (Martínez Cardós, 1972: 36). ${ }^{4}$

Debido al territorio multilingüe y multicultural que gobernaba Carlos V, el volumen de correspondencia que debía mantener la Administración de la Península con otros territorios de la corona como Nápoles, Portugal, Borgoña, Flandes, los estados alemanes, Austria, las Indias, etc. era ingente y requería por tanto de continua traducción. ${ }^{5}$ La lengua franca de esta época es sin lugar a dudas el latín, que se practica sobre todo en forma escrita, reservado especialmente para la redacción de tratados de paz o de guerra, capitulaciones matrimoniales, convenios y cartas reales, sin olvidar que era además la lengua por excelencia de la Iglesia. Sin embargo, en el plano oral, las lenguas de las cortes europeas y de la diplomacia son el italiano seguido del español (Mattingly, 1970). El francés también es una lengua con peso político, pues los dos monarcas más importantes del siglo XVI, Francisco I de Francia y Carlos V, comparten una misma lengua materna: el francés. En la Europa oriental, el latín y el alemán son las lenguas de la diplomacia más empleadas.

El Consejo de Estado creado por Carlos V en 1527 es fundamentalmente un consejo personal del monarca al que están subordinados los consejos particulares de los reinos. Es una institución de la monarquía que auxilia en asuntos generales, política internacional, guerras, paces, alianzas, matrimonios, etc. Otra de sus funciones es proponer el personal de servicio exterior como embajadores ordinarios y extraordina- 
rios; en definitiva dirige la actividad diplomática de a monarquía (Escudero, 1976). En casi todos los consejos particulares de los reinos se trataban y estudiaban asuntos extranjeros y, en consecuencia recibían y enviaban correspondencia a otros países. En época de Carlos V los secretarios de los consejos tendían a relacionarse más con sus respectivos países maternos, pues compartir la misma lengua facilitaba la comunicación. Muchos de ellos fueron los llamados secretarios de Estado y su misión era redactar despachos en otros idiomas o bien desempeñar secretarías que trataban aspectos determinados de la Administración del Imperio. Sabemos que hubo un secretario llamado Courteville que se encargaba de toda la correspondencia con Flandes y otro llamado Pfintzing que se ocupaba de la correspondencia alemana (Escudero, 1972: 169-170). Igualmente es sabido que el famoso cardenal Granvela (Granvelle) se labró su futuro en la corte española gracias fundamentalmente a su conocimiento del latín, francés, italiano y flamenco, y más tarde también del español. Utilizaba cinco secretarios a la vez a los que dictaba cartas en diferentes lenguas (Escudero, 1972: 80).

Así, al mismo tiempo que surge el Consejo de Estado, se crea como órgano auxiliar del mismo para hacer frente a la traducción de correspondencia, la llamada Secretaría de Interpretación de Lenguas a través de una Real Cédula, ${ }^{6}$ otorgada por Carlos V a favor de Diego Gracián de Alderete, discípulo de Luis Vives (Juderías Bender, 1882). El nombramiento de Secretario de Interpretación de Lenguas correspondía al monarca y se dictaba a través de la Secretaría de Estado (Escudero, 1972: 373).

Gracián de Alderete, el primer secretario que recibió este título, fue humanista y traductor de autores griegos y latinos. Anteriores a Gracián se conocen otros dos traductores, Gómez Díaz de Arabia, traductor del árabe, y Alonso de Valdés (1522) traductor de latín y secretario de Carlos V (Escudero, 1972: 67). Como Secretario de la Interpretación, Gracián traducía cartas del propio monarca sobre negocios políticos secretos y redactaba documentos oficiales en diferentes lenguas. También se ocupaba de todo lo referente a las traducciones de bulas y breves papales ${ }^{7}$ así como de otros papeles procedentes de Roma, despachos de Cruzada y, en general, de cartas de todos los Consejos (Ezquerro, 1966). Juderías Bender afirma en su artículo "Historia de la Interpretación de Lenguas" (1892: 156):

Merced a la organización que acertó a dar Gracián en esa época..., empezó a traducirse además del árabe, turco, sirio y persa, del y al latín, flamenco, toscano, alemán y francés, no solamente la multitud de papeles que llegaba de Roma, Flandes, Italia, Francia y Alemania, sino también los que iban allá...

A Gracián de Alderete le sucedió su primer hijo varón, Antonio Gracián, un eminente latinista con sólidos conocimientos del latín y del griego que le había estado auxiliando en la Secretaría. Éste aparece también de alguna forma como secretario personal de Felipe II, al servir de enlace entre dicho monarca y los secretarios de Estado, de Guerra y otros órganos (AAH, Col. Salazar, E-21, 9-359. fols. 64-65). El siguiente secretario, Tomás Gracián (AMAE, Personal, exp. 06012), también hijo de Alderete y traductor del latín, francés, italiano, portugués y valenciano se encontró ya en 1588 con un problema de intrusismo profesional que trató de solventar enviando un memorial ${ }^{8}$ al Consejo de Castilla en el que solicitaba la prohibición de esta práctica. Al parecer algunos notarios y escribanos de la corte traducían documentos para los tribunales de justicia sin poseer el debido conocimiento. Por esta razón solicita al Consejo mencionado que prohíba esta práctica que él considera perjudicial por los 
efectos legales que se pueden derivar de una traducción errónea (AHN, Consejos, Consultas de gracia, leg. 4411, f.211).

Este asunto - constante caballo de batalla para todos los Secretarios de la Interpretación - reflejado elocuentemente en el memorial de Tomás Gracián, podemos considerarlo como el germen de las sucesivas órdenes que se emitieron a mediados del XIX para regularizar la figura del intérprete jurado en la Península.

Aunque no es objeto de este estudio, un breve inciso para señalar que fuera de la Península el intérprete jurado aparece mucho antes. Al implantarse el sistema judicial español en el Nuevo Mundo, Felipe II dicta el 4 de octubre de 1563 una ordenanza por la cual se establece que en las audiencias haya intérpretes y que éstos deberán ejercer su oficio "bien y fielmente" previa declaración jurada de que realizarán su cometido "sin encubrir ni añadir cosa alguna, diciendo simplemente el hecho, delito o negocio, y testigos que se examinaren, sin ser parciales a ninguna de las partes" (Peñarroja, 2000: 162). En las ordenanzas dictadas por Felipe II se detalla la actividad de la profesión así como el salario que percibían, el horario de trabajo, la prohibición de actuar fuera de los tribunales, etc. A esta ordenanza le sucederán otras (1583, 1630) en las que se recuerda la importancia de la tarea del intérprete y las cualidades de la persona que la desempeña.

\section{La consolidación}

En los siglos XVI y XVII la Secretaría se consolida y atraviesa un periodo de equilibrio bajo lo que hemos dado en llamar la dinastía de los Gracianes, pues el cargo de secretario quedó vinculado a dicha familia durante casi 190 años con algunos periodos de interinidad en que el cargo lo ocuparon otras personas ajenas a esta familia. En cuanto a las atribuciones del secretario, que recibía, por lo general, también el nombramiento de Secretario del Rey, estaba facultado para realizar traducciones, dar fe pública de documentos, para revisarlos y corregirlos, establecer un arancel para las traducciones de particulares, así como para contratar a traductores externos (Cáceres, 2000: 122-123).

En esta primera época los Secretarios de la Interpretación de Lenguas habían recibido una educación humanista. Eran letrados de la Administración con un puesto de rango medio y pertenecían a una clase social intermedia que no era ni la nobleza ni el pueblo llano. A finales del XVI y en el XVII los Gracianes y otros Secretarios trataron de elevar su rango social convirtiéndose en Caballeros de la Orden de Santiago para lo cual había que demostrar limpieza de sangre. ${ }^{9}$ Conocían generalmente el latín, griego, francés, italiano y portugués y en algunos casos el alemán y el flamenco (Cáceres, 2000: 122). Paralelamente a la Secretaría encontramos desde comienzos del XVII a otros traductores sirviendo directamente en otros órganos de la Administración como el Consejo de Estado, la Secretaría del Consejo de Flandes (1650) y la Secretaría de Estado de la Negociación del Norte (1664), ${ }^{10}$ de los cuales al menos seis traducen del alemán y flamenco. Para distinguir a estos traductores de los de la Secretaría de Interpretación de Lenguas, los designamos traductores del Estado. Desde 1612 está documentado también el nombramiento de traductores de lenguas orientales (árabe, turco, persa, siríaco y caldeo) al servicio de los consejos. Todos estos traductores se encargaban de los documentos de naturaleza más reservada así como de la traducción de tratados y convenios (Cáceres, 2000: 243-247). 


\section{El ocaso de los Gracianes}

Con el último de los Gracianes a cargo de la Secretaría, Francisco Gracián (17141734), termina una época y da comienzo otra nueva con el nombramiento de Miguel Josef de Aoiz (1734-1744), cuando la Corona española se encuentra ya en manos de los Borbones. Aoiz, al igual que sus antecesores, también fue caballero de la Orden de Santiago. ${ }^{11}$ Seguramente obtuvo el cargo por poseer esta condición así como por sus conocimientos del inglés, flamenco y francés, idiomas que aprendió durante sus años de servicio a las órdenes del marqués de Pozobueno en Inglaterra y Flandes (AHN, Estado, leg. $\left.3421^{1}-4-\right)$.

Después de Aoiz ocuparon el cargo Domingo Marcoleta (AHN, Estado, leg. $3422^{1}$-2-) y algo más tarde Eugenio de Benavides, que alegaba conocer el latín, francés, italiano y alemán, si bien su conocimiento de este último idioma debió ser más bien superficial. El caso de Benavides es bastante insólito. En 1755 se le acusó de haber traducido erróneamente unas bulas latinas, por lo que hubo de someterse a un examen público ante un tribunal para defender su capacidad traductora, examen que superó satisfactoriamente siendo restituido en su cargo. El examen consistió en que Benavides tradujera un bulario del latín, un texto histórico del italiano y un tratado de paz del francés. Entre los miembros del tribunal examinador se encontraba Juan de Iriarte, traductor del Estado en aquella época y a quien me referiré más adelante (AHN, Estado, leg. 3441 -8-).

A Benavides le sucede Felipe de Samaniego, el cual marcará un importante hito en la historia de la Secretaría al disponer la creación de un archivo propio así como de un libro de registro. Es indudable que Samaniego poseía categoría intelectual dado que fue miembro de varias Reales Academias (lengua, historia y bellas artes). Obtuvo licencia papal para leer libros prohibidos y conocía el latín, el griego, el italiano, el francés y el inglés. Samaniego fue el traductor del famoso breve del Papa Clemente XIV, Dominis ac Redemptor, por el que se disolvió y extinguió la Compañía de Jesús (AHN, Estado, leg. 3447 -3-).

El advenimiento de una nueva casa monárquica, los Borbones, corta definitivamente el cordón umbilical con los territorios germánicos. En esta época encontramos ya un número menor de traducciones de las lenguas germánicas frente a un número mayor de traslaciones del francés, italiano y del emergente inglés. El francés había ido adquiriendo relevancia internacional desde el siglo XVI y conseguirá incluso arrebatarle al latín su estatus de primacía. La pugna latín-francés se resolverá en 1714 con la firma del tratado de Rastadt. ${ }^{12}$ Dicho tratado se redactará en la segunda lengua mencionada sancionando por tanto su uso como lengua diplomática escrita. La supremacía de la lengua y cultura francesas alcanzaron proyección mundial.

De este periodo conocemos los diccionarios que poseía la Secretaría de Interpretación de Lenguas, que reflejan el estado de la cuestión lingüística en la Península. De los 36 diccionarios que tiene en su haber hay seis que incluyen el alemán, cuatro el flamenco y dos el sueco. De estos 12 diccionarios, sólo uno, impreso en Amberes en 1650 presenta la combinación flamenco-español, casi todos los demás combinan una lengua germánica con el francés o italiano (AMAE, ms. 244). Esto indica sin lugar a dudas que para los traductores españoles el francés y el italiano eran los grandes referentes en lenguas modernas y que las lenguas germánicas se consideraban más lejanas y exóticas. 
En las postrimerías del siglo XVIII se nombrará Secretario de la Interpretación a Leandro Fernández de Moratín (1796-1811), célebre poeta y dramaturgo español, padre del llamado neoclasicismo. Moratín trató de mejorar las condiciones salariales de los oficiales que trabajaban a su cargo y continuó con la labor de archivo iniciada con Samaniego. Moratín traduce del latín, inglés, francés e italiano (Andioc, 1995).

Los traductores del Estado correspondientes a estas fechas son tres: Joaquín de Montealegre (AHN, Estado, leg. $3427^{2}$-21-), Juan Amador (AHN, Estado, leg. $3422^{1}-$ 7-) y el latinista Juan de Iriarte (AHN, Estado, leg. 3418 -7-) tío del famoso literato español Tomás de Iriarte, conocido sobre todo por sus fábulas, que posteriormente heredaría el cargo de su tío. Ninguno de estos tres traductores conoce lengua germánica alguna, sino que traducen del latín, francés e italiano y en el caso de Montealegre también del árabe (Cáceres, 2000: 243-248). A partir del siglo XVIII los traductores de lenguas orientales trabajan también para la biblioteca real, donde realizaban otro tipo de trabajos como compilar y catalogar códices antiguos, indizar manuscritos, archivar documentos, etc. El título que recibían era de "Intérprete de lenguas orientales de S.M." Se encargaban de la correspondencia con Turquía, Marruecos, Argel, Túnez y traducían también códices árabes antiguos. Casi todos ellos fueron presbíteros que habían estudiado árabe y hebreo en la universidad, aunque en el último tercio del XVIII se recurrió a extranjeros que conocieran también el turco (Cáceres, 2000: 257).

El más destacado de ellos fue Miguel Casiri, insigne arabista que alcanzó la fama en su propia época. En El Escorial llevó a cabo un importante trabajo de catalogación de códices árabes y fue profesor de esta lengua de algunos personajes distinguidos como Campomanes. ${ }^{13}$ Realizó otros trabajos de traducción de inscripciones de medallas y de un tratado de agricultura. Se sabe que traducía documentos árabes para los tribunales reales y papeles secretos para la Secretaría del Despacho de Guerra. A Casiri también se le encomendó la instrucción en lengua árabe de dos jóvenes que ya poseían conocimientos del árabe vulgar, pero esta empresa no tuvo demasiado éxito (AHN, Estado, leg. 3416 -12-). A la muerte de este arabista fue nombrado intérprete de lenguas orientales Elías Scidiac, natural de Constantinopla, que además del árabe conocía el siriaco, turco e italiano (AHN, Estado, leg. 3447 -2-).

\section{El funcionamiento de la Secretaría de Interpretación de Lenguas}

Una vez explicadas las razones por las que se crea un servicio de traducción en la Península así como el devenir de dicho organismo, se hace necesario describir más pormenorizadamente la actividad de la Secretaría para contemplar aspectos como sus funciones y obligaciones, las personas y entidades que requerían los servicios de este organismo, los tipos de documentos traducidos, las lenguas de las que se traducía, el ingreso en el organismo, así como los estudios requeridos y por último el presupuesto y sistema de derechos de traducción.

\subsection{Funciones y obligaciones de la Secretaría de Interpretación de Lenguas}

El principal cometido de la Secretaría de Interpretación de Lenguas consistía en traducir todos los documentos que llegaban a la oficina o al domicilio particular del secretario, pues ésta no obtuvo local propio hasta mediados del siglo XIX. Los documentos 
podían proceder de cualquier órgano de la Administración y se llamaban papeles de oficio. Los documentos de oficio tenían prioridad sobre los documentos particulares o de partes, además de ser confidenciales. Generalmente se tardaba unos dos días en hacer y devolver la traducción, aunque si esta era muy larga o compleja, el trabajo podía demorarse incluso hasta un par de meses. Por todos aquellos papeles de partes que se traducían, la Secretaría cobraba derechos en razón de la extensión del original y de las lenguas en que estuviera redactado. Estas traducciones eran bastante numerosas y suponían el grueso de los ingresos de la oficina y sus empleados (Cáceres, 2000: 188).

Los documentos podían llegar redactados en cualquier lengua; si en ese momento no existía nadie en la oficina que dominara el idioma en cuestión, el secretario podía encargar el trabajo a un traductor independiente que cobraba por hoja traducida. Normalmente el secretario o algún oficial realizaban la traducción que después pasaba a limpio un amanuense. Los borradores de la traducción se conservaron desde 1773 cuando así lo dispuso Samaniego ordenando que se depositaran en el archivo que creó para ello. Las minutas de las traducciones se ordenaron desde entonces numeradas y cronológicamente. De esta forma, si alguna persona deseaba una nueva copia de un documento ya traducido, no era necesario volver a realizar la traducción (Cáceres, 2000: 189).

Las traducciones se certificaban por el Secretario de la Interpretación o el oficial mayor de la Secretaría, únicas personas autorizadas para ello. El documento lo firmaba uno de los funcionarios indicados y se sellaba con el sello de la Secretaría. La certificación en la época de Samaniego era del tenor siguiente (AHN, Estado, leg. 7704, f. 588):

Certifico yo Don Felipe de Samaniego, Caballero de la Orden de Santiago, del Consejo de su Magestad, y de la Interpretación de Lenguas que esta traducción está bien, y fielmente hecha en francés del exemplar castellano que me fue remitido para este efecto, de orden del Consejo, por Don Antonio Martinez de Salazar su escribano de Camara y Gobierno. Madrid, $y$ Setiembre veinte $y$ seis del mil setecientos setenta y quatro.

Este modelo de certificación se mantuvo hasta mediados del siglo XIX. Para la legalización de bulas, los secretarios Benavides y Samaniego utilizaban las siguientes rúbricas (AMAE, ms.244) respectivamente, según figura en un oficio de la Comisaría General de Cruzada del 10 de mayo de 1773:

Eugenius de Benavides Interpretationis Linguarum Secretarius, subscripsi suo exemplari concordavi.

Infrascriptus, Divi Jacobi Ordinis Egnes, Regi a Conio atque a secretis, ac Conventui Interpretum Linguarum ab ipso Rege praefectus, ad exemplar authenticum hoc castigavi.

Estas rúbricas se incluían en todas aquellas traducciones que se realizaban del latín al castellano y que posteriormente salían a imprenta. Los secretarios también podían añadir la legalización al final del documento a instancias del interesado en el idioma pertinente (normalmente latín, castellano y francés). Además de las traducciones al castellano, con bastante frecuencia, se realizaban también traducciones inversas, casi siempre al latín, al francés o al italiano. Sin embargo, a mediados del siglo XIX dejaron de realizarse traducciones a otros idiomas que no fuera el castellano, pues los representantes de otras naciones expresaban su malestar si así se hacía y porque se consideraba que un traductor español no podía redactar con la misma 
corrección en una lengua extranjera. Así lo afirma el secretario Ceferino de Cevallos en oficio enviado al ministro de Estado el 8 de diciembre de 1850, cuando se le pidió que realizara una traducción al francés de un pliego de condiciones (AMAE, ms. 244, f.627).

Pese a todo, se ha podido constatar que en época de Samaniego se realizaban numerosas traducciones inversas que legalizaba el propio secretario con la siguiente rúbrica (AHN, Estado, leg. 7704, f. 588):

Nous Don Philippe de Samaniego Chevalier de l'ordre de Saint Jacques du Conseil de Sa Majesté Catholique son secretaire et chargé du Bureau de l'interpretation des lángues: certifions et attestons à tous ceux qu'il appartiendra que la traduction ci dessus est exacte et reponde en tout a l'acte de procuration que le precede écrit en langue espagnole: c'est pour quoi nous avons signé à Madrid ce trentième Avril mille Septent Soixante qatorze.

\subsection{Personas y entidades que solicitaban los servicios de la Secretaría}

Los documentos que llegaban a la Secretaría de Interpretación de Lenguas procedían de todos los órganos de la Administración del Estado. Estos, por tanto, variaron en el transcurso de los años en función de las modificaciones y atribución de competencias de dichos órganos. Así, a comienzos del siglo XVI, la Secretaría de Lenguas recibía encargos de todos los consejos: del Consejo de Estado, del Consejo de Inquisición, del Consejo Real de Castilla, del Consejo de Indias, del Consejo de Hacienda, etc. Dado que los consejos eran una suerte de ministerios y funcionaban al mismo tiempo como órganos legislativos, consejos de administración y tribunales de apelación, trataban todas las cuestiones por escrito y con una exasperante lentitud, que puso a prueba la paciencia de más de un secretario (Desdevises, 1989: 292). Dichos órganos solían disponer de sus propios traductores, pero la Secretaría de Interpretación de Lenguas también realizaba con frecuencia este tipo de traducciones sin olvidar que los primeros Gracianes servían directamente a los monarcas y que traducían cartas reales, patentes de embajadores y numerosa correspondencia diplomática como ya he señalado.

En los siglos XVI y XVII la Secretaría de Interpretación de Lenguas recibía numerosos encargos de los consejos y sus secretarías, pero ya en el XVIII la situación empezó a cambiar y llegaban cada vez menos papeles de oficio y más de particulares por razones de distinta índole:

1. En primer lugar el peso político de España en la comunidad internacional había ido menguando paulatinamente y en consecuencia descendió el volumen de correspondencia.

3. Los últimos Gracianes no fueron traductores tan notables como los primeros y tampoco estaban dispuestos a traducir documentos por los que apenas percibían ingresos. La traducción particular era un negocio mucho más lucrativo.

4. La Secretaría se fue así especializando en la traducción de documentos eclesiásticos y privados, mientras que los traductores del Estado, que además estaban en nómina, se especializaron en la traducción de tratados y correspondencia más confidencial.

A la Secretaría llegaban por tanto los papeles procedentes de tribunales, ya que los documentos aportados por los extranjeros inmersos en algún tipo de pleito o juicio habían de ser traducidos por ley. De esta forma la Secretaría de Interpretación de 
Lenguas se mantenía por lo general bastante ocupada. En el último tercio del siglo XVIII los documentos que llegaban a la Secretaría de Interpretación de Lenguas procedían de distintos organismos de la Administración como de la Secretaría de Cámara de Gracia y Justicia, del Consejo de Indias, de la Secretaría del Despacho de Estado, de la Cámara de Castilla, del Consejo Supremo de Guerra, de la Cámara y Gobierno del Consejo Real, ${ }^{14}$ etc. Los papeles traducidos procedían fundamentalmente de Flandes, Roma, los Estados alemanes, la Confederación Helvética, Portugal, Suecia, Francia e Inglaterra (Cáceres, 2000: 196).

En la primera mitad del siglo XIX el volumen de traducción volvió a disminuir, ya que la ley ya no exigía que todos los documentos escritos en lengua no castellana presentados ante tribunales pasaran necesariamente por la Secretaría de Interpretación de Lenguas, sino que podían traducirlos los traductores jurados de cada lugar, autorizados por un examen estatal que realizaba la propia Secretaría de Lenguas. Esta circunstancia restó gran parte de trabajo a la Secretaría, además de privarla de una importante fuente de ingresos.

Los particulares que solicitaban traducciones solían presentar generalmente documentos personales como fes de bautismo, licencias para casarse, poderes, testamentos y similares. Muchos particulares extranjeros hacían traducir diplomas obtenidos en el extranjero o papeles comerciales. De los tribunales se remitían fundamentalmente indultos, declaraciones y testimonios de extranjeros pendientes de un juicio o pleito (Cáceres, 2000: 197).

\subsection{Tipos de documentos traducidos}

Los documentos enviados de oficio a la Secretaría de Interpretación de Lenguas solían remitirlas los consejos. Del Consejo de Indias se remitían generalmente bulas pontificias, breves papales, tratados, cartas de embajadores o de cónsules y memorias, pero este tipo de documentos también eran bastante solicitados por la Comisaría General de Cruzada y por la Cámara de Castilla. La Primera Secretaría del Estado hacía traducir cartas de embajadores, de nobles extranjeros y diplomáticos y también documentos técnicos.

Entre los documentos de partes, mucho más abundantes, sobre todo a comienzos del siglo XIX, se encontraban fundamentalmente rescriptos ${ }^{15}$ y secularizaciones solicitados por clérigos y, por otro lado, fes de vida, de bautismo, diplomas, contratos, poderes, testamentos, licencias matrimoniales y otros. Así lo atestigua el mencionado Moratín en una carta enviada a Melchor Jovellanos ${ }^{16}$ el 27 de abril de 1797, cuando tomó posesión de su cargo y viéndose abrumado por la cantidad de trabajo que había en la oficina (Andioc, 1995).

Podemos distinguir por su naturaleza entre documentos jurídicos, diplomáticos y técnicos que a su vez se podrían dividir en los siguientes subgéneros:

\section{Documentos jurídicos ${ }^{17}$}

Eclesiásticos: encíclicas, rescriptos, bulas pontificias, indultos, sentencias, secularizaciones, dispensas papales, breves, preces, concesión de dispensas matrimoniales, fes de bautismo, de matrimonio y de defunción, concesión de títulos nobiliarios o nombramientos eclesiásticos.

Públicos: circulares, ordenanzas, reglamentos, contratos. 
Civiles: partidas de nacimiento, de matrimonio, de defunción, genealogías, despachos de concesión o rehabilitación de títulos nobiliarios, dispensas de residencia, fes de vida, testamentos, pasaportes, poderes y actas notariales, escrituras, capitulaciones matrimoniales, donaciones, cesiones, contratos civiles o mercantiles de toda clase y naturaleza, memorias y cuentas de sociedades.

Mercantiles: cartas de pago, escrituras de compra-venta, contratos, letras de cambio, pagarés, facturas, libros de contabilidad, poderes.

Penales: suplicatorios, autos de fe, sentencias, requisitorios, providencias, cédulas.

\section{Documentos diplomáticos}

Incluyen tratados, convenios, pactos, exequáturs, ${ }^{18}$ cartas y despachos de embajadores, memorias, patentes de cónsules, etc. Entre la correspondencia que se mantenía en la corte de Carlos III, Kleinmann distingue los siguientes tipos (en Juretschke, 1970: LII): Carta. Carta breve para comunicar y confirmar asuntos sencillos y cotidianos como por ejemplo concertar una reunión, confirmar la llegada y partida de correos, envío de documentos, etc.

Notas. Más frecuentes que las cartas. Constituía la correspondencia más habitual entre el enviado de una Corte y las autoridades y ministros del país. Las notas podían ser firmadas o verbales, aunque las primeras eran menos frecuentes.

Memorándum. En ellos se determinaba el contenido de las negociaciones verbales de cierto peso político. Se dirigía siempre a primeros ministros y servía para enumerar o resumir las partes más importantes de una misión diplomática. No llevaban encabezamiento, fórmula de despedida ni sello. Se utilizaban más frecuentemente al comienzo o en los momentos críticos de una negociación.

Memoria. De carácter más oficial y formal. Expresa una manifestación u opinión que el enviado realiza en nombre de su corte.

La memoria representa, por tanto, mediante la figura del enviado, la voluntad del soberano y detallaba una misión o la marcha de un asunto determinado. Cuando un enviado redactaba tal documento solía mantener el texto de la orden original, pero en las cuestiones importantes recibía de la cancillería una memoria ya redactada, que únicamente entregaba a las autoridades en cuestión. Por norma general, los memoranda y las memorias se redactaban en francés, mientras que las cartas y notas se escribían en italiano.

\section{Documentos técnicos}

Podemos enumerar dentro de este tipo de textos proyectos, informes, memorias, reglamentos sobre temas diversos como metalurgia, navegación, química, veterinaria, medicina, ciencias naturales y otros. Los documentos remitidos de oficio eran de lo más variopinto. En el primer libro de registro de la Secretaría de Interpretación de Lenguas están registradas, por ejemplo, las traducciones de unos impresos escritos en italiano sobre la peste que se extendió en 1781 en Salónica, Esmirna y Alexandreta (AMAE, ms. 244). El Magistrado de Sanidad de Venecia publicó un edicto acerca de este contagio y posteriormente una carta en la que se describen las precauciones que se tomaban en la República de Venecia para prevenir el contagio que se propagaba en varios puertos otomanos.

A veces llegaban también traducciones técnicas que planteaban bastantes quebraderos de cabeza a los traductores. Así se traduce en 1792 un proyecto redactado en francés por el conde Teodoro Batiani, gentilhombre de Cámara del Rey, sobre navegación en ríos contra corriente (AMAE, ms 244, f.406). Asimismo data una traducción del año 1774 de un calendario geográfico de San Petersburgo, impreso por la Academia Imperial de las Ciencias de esta ciudad (AMAE, ms. 244).

El 13 de febrero de 1781, el Secretario de la Junta de Comercio y Moneda, ${ }^{19}$ Luis Alvarado, remite un reglamento del Rey de Cerdeña sobre el modo de hilar y torcer la 
seda y solicita la traducción al castellano para instalar unas fábricas de hilado en España. El Secretario Samaniego escribe una carta a la Junta de Comercio y Moneda, el organismo que había solicitado la traducción, en la que manifiesta las dificultades que habían tenido para traducir el documento (AMAE, ms. 244).

Otro ejemplo data de 1782 cuando se le pidió a la Secretaría de Interpretación de Lenguas la traducción de una memoria sobre la forma de convertir hierro en acero. Felipe de Samaniego declinó este trabajo por considerar su conocimiento sobre esta materia insuficiente y propuso a Casimiro Gómez Ortega, profesor del Jardín Botánico, experto en química y con buen conocimiento del inglés. El Ministerio de la Marina solicitó el 13 de junio de 1782 la traducción de un proyecto en francés acerca de la conservación de agua dulce a bordo de los navíos (AMAE, ms. 244).

De las traducciones técnicas no siempre se hacía cargo la Secretaría de Lenguas; todo dependía del idioma y, por supuesto, de la disposición del Secretario a emprender una larga y difícil tarea. Moratín, por ejemplo, aunque mostró en repetidas ocasiones su preocupación para que la oficina obtuviera un mejor presupuesto y sus empleados gozaran de salarios más dignos, declinó en varias ocasiones trabajos que requerían una considerable inversión de tiempo y que resultaban molestos (Cáceres, 2000: 202).

\subsection{Lenguas traducidas en la Secretaría}

Mariano Juderías Bender señala que en la Secretaría de Interpretación de Lenguas se traducían documentos tanto de lenguas orientales como occidentales, en concreto del árabe, turco, sirio y persa, del y al latín, flamenco, toscano, alemán y francés. Si esto es cierto, Gracián Alderete había de servirse de otros traductores que le auxiliaran, pues es bastante probable que él tradujera únicamente de lenguas occidentales (latín, flamenco, italiano, francés y alemán). Aunque Juderías no menciona el portugués es seguro que se traducía también de esta lengua y del catalán según figura en el memorial ya citado de Tomás Gracián.

Así y todo, en los siglos XVI y XVII se traducía principalmente del latín, francés, italiano y flamenco y en menor medida del alemán, inglés y portugués. Con menos frecuencia se traducía también del valenciano y catalán. Las tres primeras lenguas citadas eran las más traducidas. Muy ocasionalmente se realizaban traducciones del sueco, noruego y danés. No he podido constatar ninguna traducción de ningún idioma eslavo, ni del húngaro, finés o de las lenguas romances menos usuales como el rumano. Las traducciones del árabe, siriaco, caldeo, turco y griego moderno las realizaban directamente los traductores del Estado al efecto y normalmente no llegaban a la Secretaría de Interpretación de Lenguas. En las pocas ocasiones en que la Secretaría, al menos en época de Samaniego y Moratín, se encontró con algún texto exótico, lo remitió directamente al traductor del Estado (Cáceres, 2000: 215).

Es seguro que en el último tercio del siglo XVIII solo se traducía de lenguas occidentales como expresa Samaniego en una respuesta que da al duque de Alcudia cuando éste le solicita una traducción del griego vulgar diciéndole: en la oficina se traduce del latín y de 9 ó 10 lenguas europeas y no lenguas orientales (AMAE, ms. 244: f. 477). Este secretario solicitó en varias ocasiones que se agregara a su secretaría algún traductor de lenguas orientales para poder hacer frente a los encargos en estas lenguas, si bien no me consta que su petición surtiera efecto alguno.

En cuanto a la traducción inversa llegaban con bastante frecuencia documentos para traducir al francés y latín y en menor medida, al italiano. Resulta harto difícil 
valorar la calidad de las traducciones, pues el archivo solo conserva los borradores de las traducciones, circunstancia que impide llevar a cabo un cotejo de los textos. En ciertas ocasiones, bien por error del archivero, bien porque había dos copias, se ha podido encontrar tanto el original como la traducción.

\subsection{El ingreso en la Secretaría. Estudios y conocimientos requeridos}

Como ya se ha señalado, el cargo de Secretario de la Interpretación de Lenguas quedó vinculado durante 190 años a la familia de los Gracianes, práctica común en aquella época, en la que ciertos cargos de la administración se pasaban de padres a hijos, de tíos a sobrinos u otros familiares. Con el último Gracián cambiaron las tornas. El hijo de éste (se trata del hijo del tercer Francisco Gracián) pareció demasiado joven y poco experimentado para el cargo de Secretario de Lenguas a la Administración, por lo que el título recayó finalmente sobre Miguel José Aoiz.

Los pretendientes al cargo de Secretario de la Interpretación enviaban un memorial al organismo pertinente haciendo constar sus méritos, fundamentalmente el conocimiento de idiomas, los estudios realizados y la experiencia laboral. Cuando Aoiz pretendió la plaza se presentaron junto con él otras 15 personas. Finalmente la selección se redujo a tres candidatos, entre ellos Juan Bautista Calzada, que había servido a las órdenes de Francisco Gracián durante 22 años (AHN, Estado, leg. $3422^{1}$-2-). Seguramente venció Aoiz por la experiencia que había acumulado durante sus 14 años de servicio en la embajada de España en Inglaterra, además de sus conocimientos lingüísticos. Generalmente se presentaban entre 5 y 10 candidatos y, salvo algunas excepciones, la plaza era conferida a una persona de prestigio con formación humanista (AMAE, Personal, exp. 12171).

Curiosamente, ninguno de los oficiales mayores, por muy dilatada que fuera su experiencia, lograron obtener la plaza de secretario excepto en ocasiones de urgencia, en que las proveían interinamente por ausencia, enfermedad e incluso fallecimiento del titular. Tales fueron los casos de Matías de Mur, Manuel Osorio o Carlos Bosch.

Normalmente el propio secretario elegía y contrataba a los oficiales de la Secretaría. Por lo general, echaba mano en primer lugar de los oficiales que habían servido con el secretario anterior, y que además le podían ayudar con su experiencia sobre la rutina de la oficina. Algunos de ellos como Manuel Ossorio, Juan Bautista Calzada, Matías de Mur o Agustín Álvarez Pato, sirvieron para varios secretarios e hicieron las veces de interino en caso de ausencia o enfermedad del titular. Pero a pesar de sus largos años de experiencia y reiteradas súplicas ninguno consiguió obtener la titularidad.

Suponemos que los secretarios sometían a los traductores a un examen escrito de traducción, aunque en los archivos no hemos hallado prueba de ello hasta la primera mitad del siglo XIX, cuando se conservan algunos de los exámenes que realizaron los aspirantes a traductores. De acuerdo con el expediente del traductor Juan Rizzo (AMAE, Personal, exp. 1145), en el año 1842 se estableció en la Secretaría que, por muy bajo que fuera el nombramiento (oficial supernumerario sin salario), había que superar previamente un examen. A medida que iban quedando vacantes las plazas de los oficiales superiores (por renuncia voluntaria, jubilación o fallecimiento) los últimos iban ascendiendo en el escalafón por riguroso orden de antigüedad. La 
carrera del traductor oficial era por tanto muy larga y se necesitaban muchos años para lograr un puesto y un sueldo medianos.

El examen consistía generalmente en la traducción de textos redactados en los idiomas que el candidato alegaba conocer y en una redacción en lengua castellana. Se valoraban especialmente los conocimientos de derecho y teología por la naturaleza de gran parte de los documentos que se traducían. Así, los oficiales traductores solían proceder de la rama de humanidades; eran juristas, filólogos, filósofos o teólogos. Generalmente se apreciaba también la capacidad para descifrar letras manuscritas e ininteligibles (AMAE, Personal, exp. 1145).

\subsection{Presupuesto de la Secretaría y sistema de derechos de traducción}

Hasta la época de Samaniego la Secretaría no dispuso de un presupuesto. El Secretario cobraba un salario anual por su trabajo de oficio y percibía además derechos por las traducciones que se realizaban a título particular. La Secretaría recibía en sus comienzos un estipendio de parte del Consejo de Cruzada, organismo para el que realizaba numerosas traducciones de concordatos20 y bulas. Del primer salario que tenemos noticia es el de Tomás Gracián (1576-1615) que percibía 85 maravedíes de vellón21 al año por las traducciones de Cruzada y otros 55 por ayuda de costa ordinaria22 por las traducciones que realizaba para Hacienda. Más de un siglo después, el secretario Miguel José de Aoiz se lamentó en un memorial de realizar un sinfín de traducciones para todos los Consejos sin percibir por ello ningún tipo de asignación, salvo la ya mencionada del Consejo de Cruzada, que en su época (primera mitad del siglo XVII) ascendía a 500 ducados.23 La queja de Aoiz se reflejó en una consulta del Consejo, que resolvió conceder un salario a Aoiz de 236.000 maravedíes al año, al igual que lo percibieron otros secretarios anteriores como Francisco Gracián (AHN, Estado, $34221-2-)$.

Al siguiente secretario, Benavides, se le asignó un sueldo de 6.241 reales de vellón ${ }^{24}$ al igual que a su antecesor (AHN, Estado, $3441^{1}-8$-). Hacia la época final de su cargo, Benavides llegó a cobrar 11.000 reales de vellón. Su inmediato sucesor, Samaniego, ingresaba un sueldo por secretario y casa de aposento. ${ }^{25}$

Independientemente del sueldo fijo, existía un arancel en función del idioma que se aplicaba a los trabajos de traducción. Del total cobrado por una traducción el secretario solía pagar una tercera parte al traductor que la había realizado. Suponemos que el resto lo dedicaba a sufragar los gastos de la oficina como papel, tinta, muebles y enseres, diccionarios, y a pagar al oficial de partes y a los escribanos. De esta forma la Secretaría prácticamente se autofinanciaba, ya que el número de traducciones fue bastante crecido hasta la primera mitad del siglo XVIII, de acuerdo con Samaniego. Posteriormente el número de documentos decreció, y consecuentemente menguaron los ingresos de los traductores que trabajaban a las órdenes del secretario. Con Samaniego y posteriormente con Moratín, se estableció un nuevo arancel y un presupuesto para la oficina que asignaba sueldos, aunque bajos, para los oficiales de la secretaría (Cáceres, 2000: 232).

De la época de los primeros Gracianes no consta ningún papel acerca del presupuesto de la Secretaría ni del arancel que se cobraba por las traducciones. Sin embargo, el arancel debió ser superior en el siglo XVII que en el XVIII como se desprende de la siguiente afirmación de Samaniego (AMAE, Personal, exp. 1277): 
Mientras que antes se pagaba por cada hoja de 18 a 20 renglones y de 32 a 33 letras cada uno por la traducción de piezas de Roma 10, ahora se pasa a 5 reales por traducir del latín, 4,5 reales por italiano.

Según este mismo secretario, los ingresos de la oficina eran muy superiores antes, aunque no especifica el año, no sólo por el mayor arancel sino por el mayor número de traducciones que se realizaban. El descenso del volumen de trabajo se debió, entre otras causas, a las disposiciones de la Pragmática ${ }^{26}$ de 1768 , por la cual se prohibía la libre introducción de bulas, breves y rescriptos del Papa, que menguaba notablemente el volumen de documentos susceptibles de ser traducidos. Samaniego fue además el primero en solicitar que el título de secretario gozara de los mismos honores que los secretarios de otros consejos y tribunales y tuvo por ello que satisfacer una serie de impuestos (AHN, Estado, leg.51414 -1- f.20).

Al ser Samaniego el primero en solicitar los honores de secretario fue eximido de pagar la media anata, un impuesto que debían satisfacer todos los secretarios por su título. En 1797 Moratín solicitó un aumento del arancel que le fue denegado con el argumento de que la última subida se había realizado en 1783. Después de un ir y venir de cartas entre Moratín y el Consejo de Estado se aprobó el siguiente arancel, que traslado aquí a título de ejemplo (AMAE, ms. 244, f. 508):

Arancel aprobado en 1797

\begin{tabular}{|l|l|}
\hline Idiomas & Reales de vellón \\
\hline Inglés, alemán, flamenco, holandés, danés y lenguas del norte & 21 \\
\hline Latín & 18 \\
\hline Francés e italiano & 15 \\
\hline Portugués o lemosino 27 & 12 \\
\hline Del castellano al latín & 21 \\
\hline Al francés o italiano & 18 \\
\hline Por copia autorizada de cualquier papel en otro idioma & 6 \\
\hline Duplicados autorizados de algún papel traducido & $\begin{array}{l}\text { el arancel del idioma original } \\
\text { menos una } 1 / 3 \text { parte }\end{array}$ \\
\hline
\end{tabular}

En cuanto al turco, árabe, rabinico moderno, ilírico ${ }^{28}$, griego vulgar, el Secretario podrá exigir los derechos que le parezcan justos según la dificultad de la traducción.

Si se presentan pergaminos deteriorados por el uso o escritos en letra grifa $a^{29}$ y de difícil lectura, cartas o papeles de gente rústica, llenos de errores ortográficos, abreviaturas, idiotismos provinciales y otras circunstancias que hagan trabajosa su versión, como también los que por las materias de que tratan piden particular estudio y asimismo los que deban publicarse impresos (en cuyo caso el esmero en el lenguaje, estilo y puntuación debe ser más grande), se le autoriza al secretario para que pueda cargar a las partes además de los derechos correspondientes aquel moderado aumento que según su conciencia y honor crea que merecen.

Derecho del Registro 1 real de vellón por los documentos de 1 sola hoja y los excediesen 1/2 real por hoja, independientemente del $n^{\circ}$. 


\section{El proyecto de los jóvenes de lenguas}

Antes de pasar a la siguiente etapa, la de la crisis y decadencia de la Secretaría, es necesario explicar el proyecto de jóvenes de lenguas. En el último tercio del siglo XVIII, Juan Bouligny y Paret, comerciante de origen francés y encargado de establecer relaciones diplomáticas con la Puerta Otomana, solicitó al Conde de Floridablanca (Primer Secretario de Estado en época de Carlos III) que le enviara jóvenes de lenguas a Constantinopla (Ozanam, 1998: 98). Como resultado de estas gestiones se nombra en 1784 a José Martínez de Hebia agregado en la secretaría de la legación de Turquía con la misión de instruirse en toda perfeccion en las lenguas turca y francesa, de manera que se ponga en estado de entenderlas, hablarlas y escribirlas con propiedad (AHN, Estado, leg. 3427 -10-). Hebia se instala en Constantinopla, pero muere al poco tiempo de llegar, a la edad de 25 años. Entonces Bouligny vuelve a contactar con Floridablanca y le sugiere crear en Constantinopla un colegio para instruir a jóvenes españoles bajo una estricta disciplina, proyecto que emula a la Escuela de Enfants de Langues de París.

Este plan enlaza directamente con el que Floridablanca ya había propuesto en 1782 al ya citado Miguel Casiri. Según Casiri esta idea no era nueva, pues hubo una propuesta similar en época de Fernando VI, pero que no llegó a desarrollarse. La iniciativa truncada consistió en traer a la corte española a unos colegiales de Roma que supieran árabe. Casiri, cuando recibió a su vez esta propuesta, se opuso a ella aduciendo que los jóvenes que estudiaban en el Colegio Romano solo aprendían la escolástica en latín y no sabían más que árabe vulgar. En realidad, Floridablanca deseaba algo más que la simple formación de intérpretes, pues su proyecto incorporaba el aprendizaje del arte de la diplomacia. Así pues se nombra en 1785 a otro joven de lenguas en la legación turca y a otros cuatro agregados para cubrir puestos en las embajadas de España en Viena, Suecia, Dinamarca y Rusia (Ozanam, 1998: 98) Sin embargo, el proyecto de crear una escuela de dragomanes no cuajó a pesar de repetidos intentos.

Desde que comenzaron a nombrarse jóvenes para marchar a embajadas en el extranjero, se les menciona de diferentes formas. Aparecen como joven de lenguas, agregado u oficial agregado. En 1796 ya se distingue claramente entre agregado y joven de lenguas. Entre 1784 y 1808 se nombra en total a 70 jóvenes con misiones en el extranjero. De estos 70, 13 reciben el nombramiento específico de joven de lenguas, agregados a alguna secretaría de legación española en el extranjero. Seis de estos 13 jóvenes se forman o prestan sus servicios en zonas del norte de Europa (La Haya, Viena, Copenhague, Estocolmo, Dresde, Munich y Berlín). Los demás son enviados a regiones de Italia, Francia, países del norte de África y Turquía. (Cáceres, 2000: 275276) Estos jóvenes que inician su carrera al igual que muchos diplomáticos, constituyen el germen de la posterior carrera diplomática, creada en 1844. La primera norma legislativa con rango de ley que regula a las Carreras Diplomática, Consular y de Intérpretes data del 24 de julio de 1870.

La edad de los jóvenes oscila generalmente entre los 20 y los 30 años y aproximadamente la mitad de ellos tiene estudios secundarios, parte de ellos cursados en el extranjero (Francia, Italia y Gran Bretaña), y la otra mitad posee estudios superiores. Varios de los jóvenes de lenguas estudiaron en el colegio francés de Sorèze donde se enseñaban lenguas modernas. En cuanto a su procedencia social, en la mayoría de los 
casos los padres de los jóvenes ejercen trabajos al servicio del Estado: son diplomáticos, oficiales superiores en la armada o en la marina, militares, consejeros y secretarios de Estado o altos cargos de la Administración. Queda patente que todas estas personas se movían en un mismo círculo ya que no es infrecuente encontrar a hermanos, primos, tíos y sobrinos en la carrera diplomática. De hecho, surgían también matrimonios entre las hijas de los protectores y los jóvenes que aspiraban a algún puesto en el extranjero (Cáceres, 2000: 276). El nombramiento como joven de lenguas constituía el primer peldaño dentro de la carera diplomática, ya que después de un periodo de formación variable en alguna legación en el extranjero, los agregados ascendían a secretarios de embajada o legación, a oficiales o volvían a España para trabajar en la Secretaría de Estado.

\section{Crisis y decadencia de la Secretaría}

Entramos ya en la etapa de crisis y decadencia de la Secretaría, que corre paralela con el periodo turbulento que atraviesa España, especialmente en época de Fernando VII. ${ }^{30}$ De 1809 a 1814 la Secretaría sufre un desdoblamiento. Había dos secretarios, uno en Madrid con el gobierno intruso y otro en Cádiz. Así, fue nombrado por la Junta Central de Sevilla Blas de Mendizábal por un breve periodo de dos años, mientras que el cargo en Madrid lo ostentaba interinamente el primer oficial de la secretaría, Matías de Mur y de los Ríos (AMAE, Personal, exp. 08747). Mendizábal ascendió al cargo de cónsul general en Marruecos por lo que fue sucedido por otro insigne escritor español: Manuel José Quintana (1810-1814) (AMAE, Personal, exp. 969). Este autor sería posteriormente cesado al regreso de Fernando VII en 1814, pero con el restablecimiento del régimen constitucional en 1820 vuelve a ser nombrado por un año. En los seis años de intervalo sirvió la plaza Pablo Lozano, bibliotecario real y traductor del Estado de lenguas orientales (AHN, Estado, leg. 34291 $-12-)$.

A partir de este momento los nombramientos para el cargo de Secretario de la Interpretación se suceden rápidamente y recaen sobre personas de dudosa capacidad traductora. Uno de ellos fue José Paspati y Bracho, que llevaba trabajando en la Secretaría desde 1820 como oficial traductor (AMAE, Personal, exp. 12047). Debió de verter no pocos desatinos si nos atenemos a las palabras de José Sabau y Blanco (1826-1833), el siguiente secretario y hombre de sólidos conocimientos (AMAE, Personal, exp. 12083). De Paspati opinaba Sabau que ignoraba no sólo las lenguas extranjeras sino la castellana. Una vez nombrado Secretario de la Interpretación, Sabau consigue colocar a un sobrino suyo, Pedro Sabau, que conocía muy bien la lengua alemana y que perteneció de hecho a la Academia Alemana-Española fundada en 1845 por Julio Kühn, traductor que también pasó por la Secretaría y posteriormente catedrático de Lengua Alemana en la Universidad de Madrid (AMAE, Personal, exp. 07188).

En este periodo dejan de proveerse las plazas de traductores del Estado. El citado Tomás de Iriarte y el intérprete de lenguas orientales, Pascual Stefani, natural de Jerusalén, (AHN, Estado, leg. $3414-10-$ ) son los últimos nombramientos de los que tengo constancia. 


\section{La recuperación}

En la etapa final desde Sabau hasta Ceferino de Cevallos la Secretaría atraviesa una época de recuperación y equilibrio, especialmente bajo el certero gobierno de Cevallos, gran administrador y defensor de los intereses de la Secretaría (AMAE, Personal, exp. 12171). Pese a sus muchos esfuerzos y que de hecho mejoraron las condiciones salariales de los oficiales traductores, éstas seguían siendo insuficientes y algunos de ellos, de sólida formación lingüística, abandonaban el puesto a la mejor ocasión. En este periodo siempre hubo en la Secretaría algún oficial que conociera el alemán o el inglés (Pedro Sabau, Melitón Bartolomé, Julio Kühn y José Ahumada). Surgen paralelamente los intérpretes jurados de tribunales, práctica que repercutía sensiblemente en los ingresos de la Secretaría, por lo que Cevallos intentó que ésta obtuviera la exclusiva de la interpretación jurada. Tras repetidas gestiones en este sentido, se dicta una Real Orden en 1843, por la cual la Secretaría de Interpretación de Lenguas es el único órgano que puede realizar traducciones oficiales en Madrid, mientras que en los demás puntos del reino dicha competencia se atribuirá a los intérpretes jurados.

A la Secretaría se le reservó la interpretación jurada de los tribunales de la Corte, así como el derecho de revisión de traducciones en caso de que las partes interesadas quedaran insatisfechas, en casos de dudas lingüísticas o terminológicas o simplemente para ratificar que una traducción era correcta y se correspondía con el original. Pese a esta salvedad, la orden repercutía negativamente en la economía de la Secretaría, pues una parte importante de sus ingresos provenían precisamente de la traducción jurada. Cevallos, en desacuerdo con está última orden, remite en julio de 1844 una carta al Primer Secretario de Estado, en la que insiste sobre la responsabilidad del traductor, especialmente cuando la naturaleza de los documentos es de índole judicial (Cáceres \& Pérez, en prensa).

Esta vez, la perseverancia de Cevallos dio sus frutos, ya que el Ministerio de Estado se plegó parcialmente a sus reivindicaciones y a partir de 1851 comienzan a examinarse en la misma Secretaría de Interpretación de Lenguas personas que, a partir de ese momento, quedan facultadas para traducir documentos del idioma o idiomas examinados con derecho a cobrar un arancel por página traducida y que reciben el título de intérpretes jurados. Mas poco duró esta medida, pues el 15 de agosto de 1853 el Ministerio de Estado emite otra Real Orden que afecta a los Ministerios de Gracia y Justicia. En dicha orden se comenta la dificultad de los candidatos a intérpretes jurados para examinarse en Madrid, pues carecen de medios para trasladarse. Se recurre así a una medida que habilita a cualquier persona entendida en el idioma de que se trate para la traducción pericial. Estos reciben un nombramiento provisional y deben prestar juramento en los actos judiciales (AMAE, ms. 244). En la orden se expresa la siguiente salvedad:

Si las partes interesadas no se conformaran con una traducción hecha por los intérpretes periciales porque crean perjudicarles por falta de exactitud o fidelidad, debe dejárseles el derecho amplio de recurrir a su costa a la interpretación central. También podrán recurrir a la Secretaría de Interpretación de Lenguas autoridades civiles y militares que consideren un asunto de tal importancia que no estimen suficiente la traducción de un intérprete jurado.

De nuevo la Secretaría pierde la exclusiva de la interpretación jurada, excepto en los casos ya citados. Esta es la situación de los intérpretes jurados hasta que aparece la 
primera norma legislativa de rango de ley que regula a las Carreras Diplomática, Consular y de Intérpretes del 24 de julio de 1870. Es la primera norma que reconoce el carácter facultativo e inamovible de los empleados de las mismas al tiempo que sienta las bases para una organización general de las funciones consulares. El nombramiento de intérprete jurado lo otorgaba el Ministerio de Estado, previo examen de aptitud en la Interpretación de Lenguas. En caso de aprobar el examen había que prestar juramento ante el gobernador civil pertinente de ejercer fielmente y en conciencia la profesión y de no cobrar por las traducciones otros derechos que los vigentes según la tarifa oficial de la oficina central. Los intérpretes ejercían sus funciones en las provincias del reino y sus traducciones seguían estando sujetas, si se solicitaba por las autoridades y tribunales particulares, a revisión por aquélla.

Para finalizar este breve repaso de la historia de la Interpretación de lenguas, quisiera añadir que este organismo sigue existiendo hoy con el nombre de Oficina de Interpretación de Lenguas. Su sede se encuentra en Madrid y depende directamente del Ministerio de Asuntos Exteriores.

\section{Conclusión}

La actividad de mediación lingüística no se circunscribe únicamente a la traducción literaria. La traducción e interpretación como instrumento de las relaciones internacionales y de la Administración se nos antoja como un mundo apasionante y un ámbito de investigación en el que aún queda mucho por explorar, especialmente en los archivos históricos. La corona española, que ejerce el dominio político en la Europa occidental de los siglos XV y XVI, crea un servicio de interpretación de lenguas que puede considerarse pionero en Europa.

Este organismo auxiliar del Consejo de Estado y posteriormente de la Secretaría de Estado atraviesa por fases de esplendor, crisis y decadencia, pero ha subsistido hasta nuestros días, lo que indica que la labor ejercida ha sido imprescindible a lo largo de todos estos siglos y en muchos aspectos_si exceptuamos la tecnologización actual de la actividad traductora_su funcionamiento no difiere mucho del de un servicio de traducción contemporáneo como puede ser el da la Unión Europea. En la Secretaría trabajaron insignes escritores y también tácitos traductores que, por desgracia, pocas veces vieron recompensados sus esfuerzos.

\section{NOTAS}

1. Órganos de administración de justicia en Castilla.

2. Gestionaba los tributos que pagaba la Iglesia a la corona.

3. Antiguo tribunal supremo en las causas sobre delitos contra la fe y sus conexos

4. En época de Carlos V existían 12 Consejos: Estado, Castilla, Aragón, Italia, Portugal, Flandes y Borgoña, Indias, Guerra, Hacienda, Inquisición, Órdenes Militares y Cruzada. En los Consejos no había división de poderes, eran órganos consultivos, legislativos y ejecutivos y las cuestiones tratadas eran numerosas y heterogéneas. Cordero Torres (1944: 38).

5. Carlos V heredó de su padre, Felipe de Borgoña, los Países Bajos, de su madre, Juana la Loca, el trono de Castilla y los territorios de ultramar, de su abuelo Fernando el Católico, la corona de Aragón que incluía Sicilia, Cerdeña y Nápoles. Como nieto del emperador Maximiliano hereda Austria, el Tirol y algunos territorios en el sur de Alemania. Lynch (1964: 35)

6. Despacho del rey, expedido por algún consejo o tribunal superior, en que se concedía una merced o se tomaba alguna providencia. 
7. Bula: Documento pontificio relativo a materia de fe o de interés general, concesión de gracias o privilegios o asuntos judiciales o administrativos, expedido por la Cancillería Apostólica y autorizado por el sello de su nombre u otro parecido estampado con tinta roja. Breve: Documento emitido por el Papa y redactado en forma menos solemne que las bulas.

8. Papel o escrito en que se pide una merced o gracia alegando los méritos o motivos en que se funda la solicitud.

9. La limpieza de sangre significaba ser cristiano viejo, es decir, no tener antepasados ni de origen árabe ni judío.

10. En 1570 Felipe II dividió la Secretaría del Consejo de Estado en dos secciones: la de Negocios del Norte para gestionar los asuntos de Francia, Flandes y el Imperio, y la de Italia para los asuntos mediterráneos. Cordero Torres (1944: 48).

11. Orden militar fundada en 1160 con el objetivo de defender de asaltos y bandidos a los peregrinos que acudían al sepulcro de Santiago, así como luchar contra el poder musulmán. Para poder ser admitido en una orden habría que demostrar limpieza de sangre.

12. Mediante la firma de este tratado firmado entre Luis XIV y el emperador Carlos VI, así como el Tratado de Utrecht, firmado en 1713, se puso fin a la Guerra de Sucesión en España y Francia salió como vencedora absoluta.

13. Importante político español en época de Carlos III y Carlos IV y uno de los ejecutores de la política ilustrada en materia de educación y finanzas. Se interesó especialmente por los idiomas, aprendiendo francés, griego, italiano, latín, árabe y hebreo. Publicó “Disertaciones históricas de la Orden y Caballería de los Templarios" (1747) ingresando al año siguiente en la Academia de la Historia. Gracias a la publicación de "Antigüedad marítima de la república de Cartago, con el periplo de su general Hannon" en 1756 ingresó en la Academia francesa.

14. A comienzos del siglo XVIII la administración sufrió una reestructuración. Los Consejos fueron perdiendo importancia paulatinamente y sus competencias las fueron asumiendo las secretarías, en concreto la Secretaría del Despacho de Estado o Primera Secretaría asumió en gran medida las funciones del Consejo de Estado.

15. Decisión del Papa, de un emperador o de cualquier soberano, para resolver una consulta o responder a una petición.

16. Importante ilustrado español, autor de la obra "El delincuente honrado". Por sus avanzadas ideas sufrió el acoso de la Inquisición, siendo encarcelado en Mallorca. Con la abdicación de Carlos IV recuperó la libertad y se unió a la causa antinapoléonica.

17. Para la clasificación de los documentos jurídicos me he basado en parte en la tipología de textos propuesta en San Ginés y Arjonilla (1996: 85-96) así como en Escriche (1847).

18. Autorización que otorga el jefe de un estado a los diplomáticos extranjeros para ejercer sus funciones en el país.

19. La Junta General de Comercio, Moneda y Minas que data de 1747 tenía la función de elevar consultar al rey para la concesión de privilegios de invención o fabricación.

20. Tratado o convenio sobre asuntos eclesiásticos que el Gobierno de un Estado hace con la Santa Sede.

21. Antigua moneda española de cobre.

22. Subvención económica para sufragar parte de los gastos de un viaje, gastos por enfermedad o cualquier otro tipo de necesidad.

23. Moneda imaginaria equivalente a once reales de vellón, aumentada en una mitad más por la pragmática de febrero de 1680, y vuelta después a su valor primero.

24. El real era de plata y equivalía a 34 maravedíes.

25. Ayuda que recibían las personas al servicio del monarca bien en forma física bien en forma monetaria para buscar posada

26. Disposición legislativa promulgada por los soberanos.

27. También llamado lemosí. Hiperónimo para designar el catalán, valenciano y mallorquín.

28. Referido al croata.

29. Letra cursiva.

30. En 1809 España es invadida por José Bonaparte y crea su propio gobierno, llamo intruso. La adeptos a Bonaparte son los llamados afrancesados. Los contrarios al régimen de Bonaparte, los independentistas, se reúnen en la llamada Junta Central para luchar contra la invasión francesa. El gobierno francés cae en 1814. Al haber dos gobiernos, algunos órganos, como la Secretaría de Interpretación de Lenguas, se duplican. 


\section{REFERENCIAS BIBLIOGRÁFICAS}

\section{FUENTES PRIMARIAS}

\section{Archivo Histórico Nacional (AHN)}

Consejos: leg. 4411

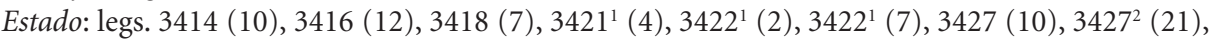
$3429^{1}$ (12), 3441 (8), 3447 (2), 3447 (3), 7704, 51414 (1)

Archivo del Ministerio de Asuntos Exteriores (AMAE)

Manuscritos: 244

Personal: expedientes: 00019, 06012, 07188, 08747, 969, 1145, 1277, 12047, 12171

Archivo de la Academia de Historia (AAH)

Colección Salazar, E-21, 9-359, fols. 64-65

Fuentes secundarias

Andioc, R. (1995): Epistolario de Leandro Fernández de Moratín, Madrid, Castalia.

Boletín del Ministerio del Estado (24 de julio de 1870): "Ley orgánica de las Carreras Diplomática, Consular y de Intérpretes," p. 337-395.

CÁceres, I. Y L. Pérez (en prensa): "Antecedentes históricos y proyección futura de la figura del intérprete jurado en España".

CÁceres, I. (2000): "La traducción en España en el ámbito de las relaciones internacionales con especial referencia a las naciones y lenguas germánicas (s. XVI-XIX)", tesis doctoral leída en la Universidad Complutense de Madrid.

Cordero Torres, J. M. (1944): El Consejo de Estado: su trayectoria y perspectivas en España. Madrid, Instituto de Estudios Políticos

Danvila Collado, M. (1885): "El Poder Civil en España”. Memoria premiada por la Real Academia Española de Ciencias Morales y Políticas en el concurso ordinario de 1883, Madrid, tomo II.

Desdevises (1989): La España del Antiguo Régimen, Madrid, Fundación Universitaria Española, Seminario Cisneros.

EsCRICHe, J. (1847): Diccionario razonado de legislación y jurisprudencia, Madrid.

Escudero, J. A. (1976): Los Secretarios de Estado y del Despacho, Madrid, Instituto de Estudios Administrativos.

Ezquerro, M. (1966): "Diego Gracián de Alderete", tesis doctoral leída en la Universidad de Toulouse.

Juderías Bender, M. (1892, febrero): "Historia de la interpretación de lenguas", Boletín del Ministerio del Estado, p. 154-161.

Juretschke, H. (1970): Berichte der Diplomatischen Vertreter des Wiener Hofes aus Spanien in der Regierungszeit Karls III. Edición anotada y comentada por Hans-Otto Kleinmann, Madrid, Görres-Gesellschaft/CSIC, tomo I.

Lynch, J. (1964): Spain under the Habsburgs. Empire and Absolutism (1516-1598), New York: Oxford University Press, vol. I

Martínez Cardós, J. (1972): “Estudio preliminar", in Primera Secretaría de Estado. Disposiciones orgánicas de política exterior (1705-1936), de Carlos Fernández Espeso y José Martínez Cardós, Madrid, Secretaría General Técnica, Ministerio de Asuntos Exteriores.

Mattingly, G. (1970): La diplomacia del Renacimiento, Madrid, Instituto de Estudios Políticos.

Ozanam, D. (1998): Les diplomates espagnoles du XVIII siècle. Introduction et répertoire biographique (1700-1808), Madrid-Bordeaux, Casa de Velázquez. Maison de Pays Ibériques.

Paz y Meliá (1901): "Otro erasmista español: Diego Gracián de Alderete”, Revista de Archivos, Bibliotecas y Museos, no 5.

Peñarroja Fa, J. (2000): "Historia de los intérpretes jurados", in José A. Sabio \& José Ruiz \& Jesús de Manuel (eds.) Conferencias del curso académico 1999/2000, Granada, Comares, p. 161-195.

San Ginés, P. y E. Ortega Arjonilla (eds.) (1996): Introducción a la traducción jurídica y jurada, Granada, Comares. 